codes' (page 20), or the confusion of 'trusting' with 'trustworthy' (page 65). There is also a great deal of generalisation, particularly stereotyped in relation to other cultures. It is simply not accurate to say, as the authors do on page 63 , that abortion of female fetuses and murder of baby girls in parts of India is the result of ' $a$ centuries-old tradition, sustained by ceaseless grinding poverty and social convention'. The problem is relatively recent, created not only by new technologies but also by the extension of the formerly upper-class habit of providing large dowries to the statusseeking middle and lower-middle classes. That is what has made girls an expensive liability.

Overall, this is a book which is certainly needed in social work practice, and $I$ hope it succeeds in reaching its principal audience. More academic readers are less likely to find it satisfying.

DONNA DICKENSON

Senior Lecturer, School of Health and Social Welfare, The Open University

\section{Holding On?}

Hazel McHaffie, Cheshire, Books for Midwives Press, 1994, 217 pages, $£ 9.95$

Holding On? is a powerful novel about a pre-term infant on the edge of viability and the debate about whether he should be kept alive on life-support. It will make a captivating read for health care professionals and anyone with a more academic interest in this complex subject.

The book is beautifully written. Each character is convincingly portrayed and their individual experience skilfully brought to bear on the ethical dilemma being examined. Hazel McHaffie succeeds in creating a world where the reader is able to empathise with many opposing ethical viewpoints through the lives of those associated with the fictional neonatal unit. The perspectives of the parents, consultant, registrar, junior doctor, staff midwife, nurses, chaplain and social worker are all examined. The writer uses the device of the different 'voices' of the characters to present strong arguments and counterarguments in the debate about continued life-support. The latter is a trait which Gillon (1) believes is 'at the heart of bioethics'. The work therefore deserves to be recognised as a strong contribution to the field of medical ethics. The issues concerning euthanasia, quality of life, paternalism and rights are all explored. These occur within the context of societal taboos about death, personal experiences of bereavement and infertility, strong religious beliefs and differing personalities. The result is a thought-provoking book that lives in the memory.

The novel is ambitious in its attempt seriously to address so many ethical questions in such a compact and unusual format. Once or twice there is a slightly contrived feel. This occurs both in establishing the characters at the start and in the extent to which so many of them share a personal investment in the question of whether to discontinue life-support. All that is required of the reader is a momentary effort consciously to suspend disbelief, a task that will not be arduous given the quality of the writing. Neither will the effort go unrewarded, given the important insights the novel has to offer.

\section{Reference}

(1) Gillon R. Editorial - A personal view: Ethics of genetic screening: the first report of the Nuffield Council of Bioethics. Fournal of medical ethics 1994; 20: 67-68, 92.

ALISON DINES

Department of Nursing Studies, King's College, London

\section{Healthy respect: ethics in health care (2nd ed)}

\section{R S Downie and K C Calman, Oxford, Oxford University Press, 1994, xviii + 291 pages, $£ 35.00$ hard cover}

When the first edition of this book appeared, serious provision of ethics teaching for medical doctors was, in Britain, effectively confined to specialist postgraduate courses. Eight years later, the provision of such teaching at the medical undergraduate level is still a rarity. Healthy Respect, whilst aimed more widely than at clinical students alone, has during that time offered such students and their teachers a distinct, synoptic and concise resource for exploring the moral questions typical of health care practice. It still does, and its second edition is to be welcomed as much for continuing that provision as for the few revisions or enlargements that it contains. The authors' introduction specifies their

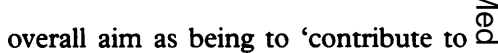
the improvement of the practice of health care' (page 5) and I have no $\overline{\overline{0}}$.

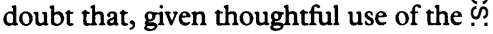
book by clinicians in training or in practice, that aim is capable of being realised. I would qualify this opinion only by observing that reflection on $\bar{\sigma}$ moral issues doesn't in itself lead to $\bar{\sigma}$ the taking of better decisions; the out- $\mathbb{D}$ come of moral reflection is underdetermined by its processes. This is an $\omega$ obvious point, of which the authors are $\overrightarrow{0}$ well aware, but which is understated in the book; many of its intended users $\vec{\omega}$ might be philosophically somewhat? innocent, and could in consequence $\overline{3}$ think that the book's specific objec- i tives (page 7) will automatically follow from working through it.

The book is in two parts, of which o the first is a preparatory study of some of the constituents of moral and practical reasoning as it concerns health care provision; the second is a sequence of $\mathbb{D}$ applied studies, covering a familiar $\stackrel{\varnothing}{\varnothing}$ range of specific health care contexts, in which the general considerations of Part One are brought to bear. The authors describe Part One as an esszy in moral philosophy, but I thought th of description misleading and over-amb tious. Rather it is a commendate introduction to how moral values are located amongst other kinds of values, and how they stand in relation to relevant scientific and statistical knowl- $\stackrel{\mathbb{Q}}{Q}$ edge and judgment, to the clinician's $\overrightarrow{\vec{F}}$ practical skills, to the bases of logical 윽 reasoning and, less convincingly, to a selection of alternative specific valuesystems or 'models of man'. Inevitably in a brief work that has so broad a scope, the coverage is uneven, and the level is professedly introductory for the most part. The only dimension in which I found this a real difficulty $\delta$ concerns the too-simple and insufficiently-critical establishment of auton- 음 omy as a foundational value, $\rightarrow$ accounting for all the more specific values or 'principles' which the authors consider as defining the moral vocabu- $\sigma$ lary of health care practice. A brief $\mathrm{N}$ acknowledgement of philosophical (as $\mathrm{N}$ distinct from the merely credal) alter- $\omega$ natives to this approach would resolve this problem. Part One is moreovere well-structured, with the possible $\frac{}{\Phi}$ exception of its last chapter on logical $\stackrel{\oplus}{+}$ argument which might have been $\square$ better located earlier on.

Part Two's rationale, applying the understandings and conclusions of $\frac{O}{\mathbb{P}}$ Part One to specific problems, is an 2 attractive one, and on its own terms the execution of Part Two broadly 